\title{
Pharmacokinetic-pharmacodynamic modeling of tylosin against Streptococcus suis in pigs
}

Lingli Huang ${ }^{1,2,3}$, Haiyang Zhang ${ }^{2,3}$, Mei Li ${ }^{2,3}$, ljaz Ahmad ${ }^{4}$, Yulian Wang ${ }^{2,3^{*}}$ (D) and Zonghui Yuan ${ }^{1,2,3^{*}}$

\begin{abstract}
Background: The aim of this study was to optimize the dosage regimen of tylosin against S.suis in Pigs using pharmacokinetic-pharmacodynamic (PK-PD) modeling. The antibacterial activity of tylosin against S.suis CVCC606 was investigated in Mueller Hinton (MH) broth and serum. The objectives of this investigation were to study the PD data of tylosin against S.suis CVCC606 and the PK data of tylosin in healthy and diseased model of pigs and formulate a rational dosage regimen for the treatment of pig streptococcosis.

Results: The minimum inhibitory concentrations (MIC) were $0.25 \mu \mathrm{g} / \mathrm{mL}$, and the minimal bactericidal concentrations (MBC) were $1 \mu \mathrm{g} / \mathrm{mL}$ in $\mathrm{MH}$ broth and serum. The killing curve showed time-dependent activity and weak concentration-dependent antibacterial activity. A pig pneumoniae model of $\mathrm{S}$. suis infection was built by inoculating subcutaneously with S. suis CVCC606. Tylosin was (10 mg/kg b.w) administered intramuscularly (IM) to the healthy and S.suis infected pigs, The pharmacokinetic properties, including area under the curve(AUC), peak concentration $\left(C_{\max }\right)$ and time to reach $C_{\max }\left(T_{\max }\right)$, were determined in plasma using UV-HPLC method. The AUC, $C_{\max }$ and $T_{\max }$ in plasma of healthy and infected pigs were $10.80 \pm 2.20$ and $10.30 \pm 3.46 \mu \mathrm{g} . \mathrm{h} / \mathrm{mL}, 2.06 \pm 0.43$ and 2 . $37 \pm 0.38 \mu \mathrm{g} / \mathrm{mL}, 1.95 \pm 0.22$ and $1.58 \pm 0.49 \mathrm{~h}$, respectively.

Conclusions: The in vivo PK and in vitro PD data were integrated to determine the surrogate marker of antibacterial activity, $C_{\max } / \mathrm{MIC}$, AUC/MIC and T>Micwere 8.90, 43.21, 8.86 for healthy pigs, and 9.76, 41.18, 7.56 for infected pigs, respectively. Ex vivo AUC/MIC data were integrated with ex vivo bacterial count to calculate the values for bacteriostatic and bactericidal action, which were $10.67 \mathrm{~h}$ and $49.66 \mathrm{~h}$ for healthy pigs, $11.73 \mathrm{~h}$ and 43 . $03 \mathrm{~h}$ for pigs infected with S.suis. A dosage regimen of $5.32-19.50 \mathrm{mg} / \mathrm{kg}$ b.w. every $24 \mathrm{~h}$ should be sufficient for tylosin against S.suis.
\end{abstract}

Keywords: Tylosin, Streptococcus suis, Pig, Dosage regimen, PK/PD modeling

\section{Background}

Streptococcus suis is a Gram-positive facultative anaerobe and increasingly emerging zoonotic infection with a global distribution [1] . The most common clinical syndrome casued by Streptococcus suis are porcine meningitis, encephalitis, pneumonia, endocarditis, polyserositis arthritis and septicemia [2, 3]. Among the 35 serotypes

\footnotetext{
* Correspondence: wangyulian@mail.hzau.edu.cn; yuanzongh@126.com.cn ${ }^{2}$ National Reference Laboratory of Veterinary Drug Residues (HZAU) and MOA Key Laboratory for the Detection of Veterinary Drug Residues in Foods, Wuhan, Hubei, China

${ }^{1}$ MOA Laboratory for Risk Assessment of Quality and Safety of Livestock and Poultry Products, Wuhan, Hubei, China

Full list of author information is available at the end of the article
}

of S. suis, serotype 2 is a predominant isolate from diseased animals and humans [4-6]. This microorganism is responsible for causing diseases in various species including human, mammals and birds. Contaminated raw and undercooked pork is the major source of transmission of this organism $[7,8]$. S. suis has negative impact on pig industry and causes severe economic losses. $S$. suis is usually treated by Tetracyclines and Macrolides in veterinary medicine, but an increasing emergence of resistance against Tetracyclines has been widely reported in recent years [9], so Macrolides are widely used for the treatment of infection caused by $S$. suis.

Tylosin belongs to the group of 16-member-ring macrolides, which was first derived from Streptomyces 
fradiae cultures in 1960 [10]. Due to its bacteriostatic action against Gram-positive bacteria, anaerobic bacteria and Mycoplasmas [11], tylosin has been widely used to treat pneumonia, arthritis, respiratory tract infections, porcine streptococcosis and other infections in veterinary medicine $[12,13]$. Tylosin is widely used as antimicrobial agent in China and administered through pareteral or oral route. The Pharmacokinetics study of tylosin has been described in a variety of animals including hens [14], broiler chickens [15], goats [16], cows [17] and dog [18]. However, there are limited data available on the Pharmacokinetics/pharmacodynamics model of tylosin in pigs [19].

PK-PD model is widely used in the determination of a dosage regimen for an antimicrobial, which can reflect the relationship of drug, bacteria and animals. The impetus to optimize dosage schedules of antimicrobial drugs has been driven not only by increased knowledge of bacterial killing mechanisms, which may be concentration-dependent, time-dependent or co-dependent, but also by the results of laboratory animal studies, target species investigations and clinical trial outcomes [20].

In this investigation, the PK data of tylosin were examined in healthy and diseased model of pigs. The purposes of the study were (1) to establish the experimental model of porcine streptococcosis, and determine PK data of tylosin in healthy and S. suis infected pigs after IM administration at a dose of $10 \mathrm{mg} / \mathrm{kg}$. (2) To investigate the in vitro PD data of tylosin against $S$. suis in $\mathrm{MH}$ broth and serum, and investigate the ex vivo activity of tylosin in serum. (3) To combine MSW theory with traditional PK-PD model using the parameters $\left(\mathrm{T}_{>\mathrm{MPC}}, \mathrm{T}_{\mathrm{MSW}}\right.$ and so on) to predict the emergence of the bacterial resistance. It is proposed that these parameters were used to formulate a rational dosage regimen for the treatment of pig streptococcosis, which will provide maximal efficacy and minimal opportunity for the emergence of bacterial resistance.

\section{Results \\ Pharmacodynamics \\ MICs, MBCs and MPC of tylosin against S. suis CVCC606}

The MIC values of tylosin against the strain of $S$. suis CVCC606 were $0.25 \mu \mathrm{g} / \mathrm{mL}$, and MBC values are $1 \mu \mathrm{g} /$ $\mathrm{mL}$ in MHB and serum obtained from pigs. MPC value of tylosin against $S$. suis CVCC606 was $1 \mu \mathrm{g} / \mathrm{mL}$, MSW was $0.25-1 \mu \mathrm{g} / \mathrm{mL}$, explaining the resistant mutant selection window is narrow. We found that in the presence of serum, the antimicrobial effect of tylosin in serum was the same as in broth. So it had a great clinical significance to study the antimicrobial effect of tylosin in vivo.

\section{Time-kill curve}

The time-dependent feature of tylosin against S. suis was demonstrated according to the killing profiles (Fig. 1), the increasing rate of killing was observed by increasing the time that $S$. suis was exposed to tylosin, meanwhile the killing profiles also showed a weak concentration-dependent
A

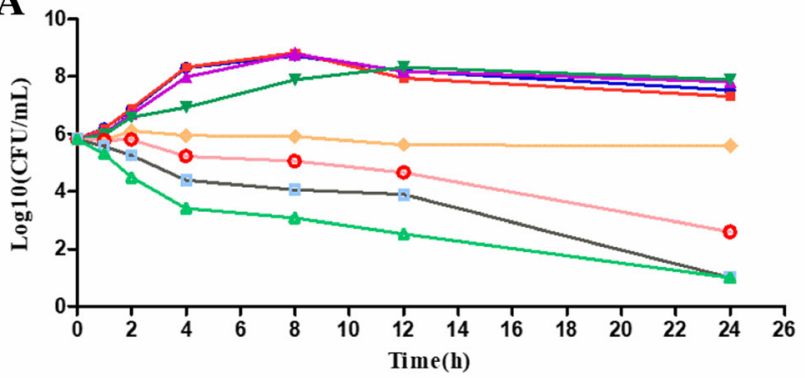

B

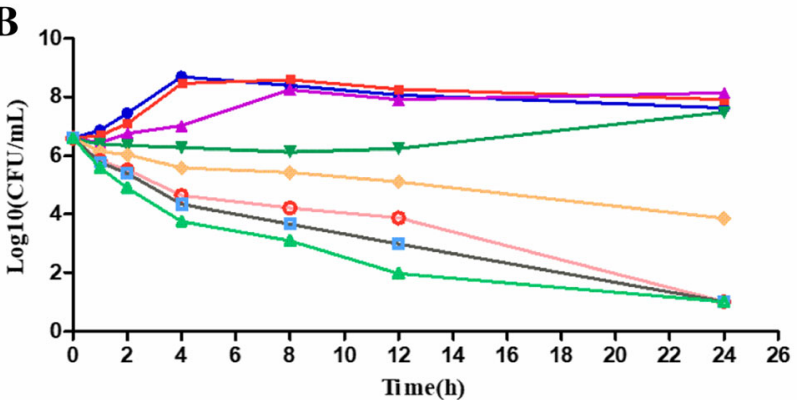

$\rightarrow$ Control

$\rightarrow 1 / 4 \mathrm{MIC}$

$+1 / 2 \mathrm{MIC}$

$\rightarrow 1 \mathrm{MIC}$

$\rightarrow 2$ MIC

- $4 \mathrm{MIC}$

- $=8 \mathrm{MIC}$

$₫ 32 \mathrm{MIC}$

Fig. 1 Killing curve of tylosin against S. suis in broth (a) and serum (b) measured at pre-determined time. The $x$-axis was the $0-24 \mathrm{~h}$ incubation time point; $y$-axis was the count numbers exposed to a series of concentrations of tylosin 
feature, and the increasing rate of killing was observed by the increasing concentration of tylosin.

\section{PAE of tylosin against S. suis CVCC606}

The PAEs for tylosin against S. suis were displayed in Table 1, which showed that the durations of PAE were directly related to the exposure time, it lasted longer when the bacteria were exposed to tylosin for 2 hours than those for 1 hour.

\section{Ex vivo antibacterial activity of tylosin against $S$. suis CVCC606}

For serum samples collected from all healthy pigs at 0.5 , $1,1.5,2,3$ and $4 \mathrm{~h}$, tylosin resulted in a $>3 \log _{10}$ reduction in viable bacterial count after $24 \mathrm{~h}$ of exposure (Fig. 2). For samples collected at $0.17,0.33$ and $6 \mathrm{~h}$, tylosin resulted in $a<2 \log _{10}$ reduction in viable bacterial count after $24 \mathrm{~h}$ of exposure. No bacteriostatic or bactericidal effects were observed from serum samples collected at 8, 10 and $12 \mathrm{~h}$. For serum samples collected from all pigs with S.suis at $0.33 \mathrm{~h}$, tylosin exerted a very strong bactericidal effect, and the other samples were similar to the samples collected from healthy pigs.

\section{Pharmacokinetics}

\section{Experimental model of porcine streptococcosis}

When the experimental model of the porcine streptococcosis was successfully established, the pigs exhibited obvious clinical symptoms, such as roughened body coats, loss of appetite, elevated body temperature (40.0 to $42.0{ }^{\circ} \mathrm{C}$ ), and were reluctant to rise and lame in one or more legs, a few of them exhibited severe central nervous system signs such as head tilt, nystagmus, tremors, prostration and opisthotonus.

\section{Pharmacokinetics of tylosin in pigs}

Serum concentrations of tylosin after IM dosing in healthy pigs and diseased pigs were illustrated in Fig. 3. Tylosin concentration-time profiles in serum were described by mono-compartmental with a first order absorption phase in all pigs.

The PK parameters of tylosin were illustrated in Table 2. Absorption and elimination of tylosin after IM administration at a dose rate of $10 \mathrm{mg} / \mathrm{kg}$ were rapid in both healthy pigs and diseased pigs, $\mathrm{T}_{1 / 2} \mathrm{k}_{\mathrm{a}}$ were $1.347 \mathrm{~h}$ and $1.060 \mathrm{~h}, \mathrm{~T}_{1 / 2} \mathrm{k}_{\mathrm{e}}$ were $1.354 \mathrm{~h}$ and $1.152 \mathrm{~h}$, respectively. Means $C_{\max }$ of $2.056 \mu \mathrm{g} / \mathrm{mL}$ (healthy) and 2.372 ( $S$.

Table 1 PAEs of tylosin against S. suis CVCC606

\begin{tabular}{lll}
\hline Concentration & Expose $1 \mathrm{~h}$ & Expose $2 \mathrm{~h}$ \\
\hline MIC & 0.21 & 1.80 \\
2MIC & 1.43 & 3.43 \\
4MIC & 2.15 & 4.21 \\
\hline
\end{tabular}

suis infectious) were reached at $1.948 \mathrm{~h}$ and $1.548 \mathrm{~h}$. The area under concentration-time curve (AUC) in both healthy pigs $(10.804 \mathrm{~h} \cdot \mu \mathrm{g} / \mathrm{mL})$ and diseased pigs $(10.297 \mathrm{~h} \cdot \mu \mathrm{g} / \mathrm{mL})$ were similar. The differences in $\mathrm{K}_{\mathrm{a}}, \mathrm{K}_{\mathrm{e}}$, $\mathrm{T}_{1 / 2} \mathrm{k}_{\mathrm{a}}, \mathrm{T}_{\max }$ and $C_{\max }$ were significant $(P<0.05)$. The fast elimination of tylosin from serum was indicated by the values of MRT.

\section{PK-PD modeling}

\section{In vivo $P K-P D$ parameters}

Integration of in vivo $\mathrm{PK}$ and in vitro $\mathrm{PD}$ data of tylosin were represented in Table 3 as the indices $\mathrm{AUC}_{24 \mathrm{~h}} / \mathrm{MIC}$, $\mathrm{AUC}_{24 \mathrm{~h}} / \mathrm{MBC}, C_{\max } / \mathrm{MIC}, C_{\max } / \mathrm{MBC}, \mathrm{T}_{>\mathrm{MIC}}, \mathrm{T}_{>\mathrm{MBC}}$. The mean AUC/MIC ratios in serum collected from the healthy pigs and diseased pigs were 43.216 and $41.188 \mathrm{~h}$, respectively. $C_{\max } / \mathrm{MIC}$ ratios were 8.900 and 9.768, $\mathrm{T}_{>\mathrm{MIC}}$ were 8.863 and $7.568 \mathrm{~h}$, respectively.

\section{Ex vivo PK-PD parameters}

The ex vivo $\mathrm{AUC}_{24 \mathrm{~h}} / \mathrm{MIC}$ ratios of tylosin were presented in Table 4 after IM administration at a dose rate of $10 \mathrm{mg} / \mathrm{kg}$. The ex vivo $\mathrm{AUC}_{24 \mathrm{~h}} / \mathrm{MIC}$ were calculated by dividing the AUC values with in vitro MIC values. $\mathrm{E}$ was calculated by counting the change in the bacterial count $(\log 10 \mathrm{cfu} / \mathrm{mL})$ in the serum sample harvested from different time points.

\section{Sigmoid $E_{\text {max }}$ model}

Data derived from PK-PD modeling of the ex vivo growth inhibition curves were presented in Table 5 and Fig. 4. For serums of healthy pigs and diseased pigs, the values of $E_{\max }$ of healthy and diseased pigs were 3.23 and 3.345 , respectively. $E_{\max }$ values were similar and indicated a high level of attainable bacterial killing in serum.

\section{Dosage regimen}

Parameter values and corresponding dosage of tylosin achieving different antimicrobial activity were exhibited in Table 6. The value of ex vivo AUC/MIC obtained for bacteriostatic action in serum from diseased pigs was 11.736. Hence, for the MIC of $0.25 \mu \mathrm{g} / \mathrm{mL}$, the lowest dose providing bacteriostatic activity is $5.320 \mathrm{mg} / \mathrm{kg}$, the calculated dose for antibacterial activity of killing 99.9\% of S. suis strains is $19.507 \mathrm{mg} / \mathrm{kg}$, which the corresponding value of AUC/MIC was 43.032, assuming a dosage interval of $24 \mathrm{~h}$. According to the calculation, For the clinical application of tylosin against $S$. suis, the dosage regimen of $5.320-19.507 \mathrm{mg} / \mathrm{kg}$ every $24 \mathrm{~h}$ for IM administration was recommended.

\section{Resistance risk assessment of tylosin}

The results were presented in Table 7, and showed that drug-resistant strains don't appear selectively when the concentration of tylosin was lower than $0.25 \mu \mathrm{g} / \mathrm{mL}$. 

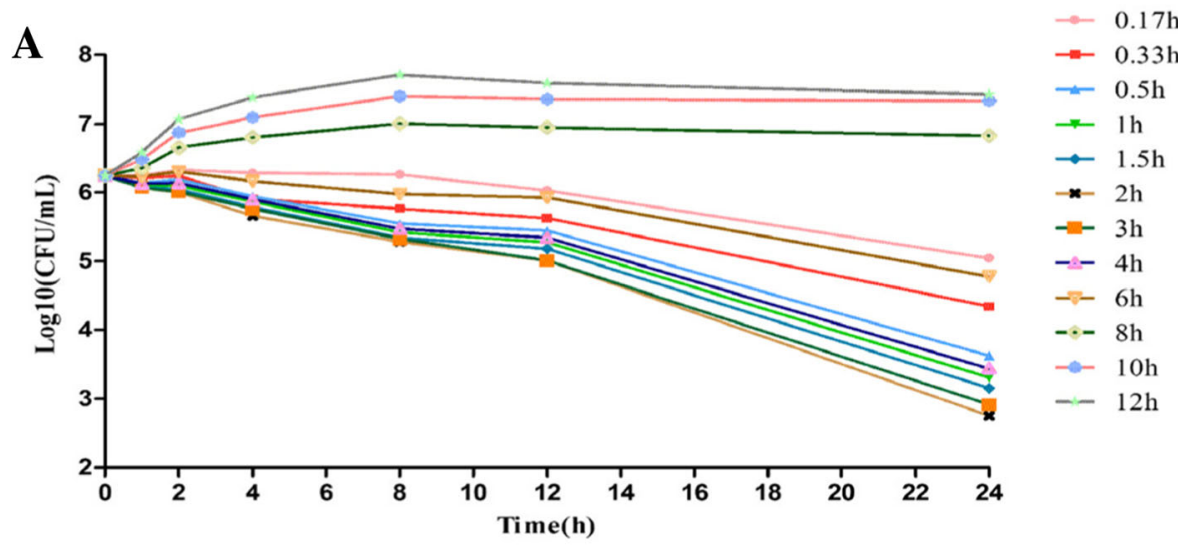

$-0.33 \mathrm{~h}$

$-0.5 \mathrm{~h}$

$\rightarrow 1 \mathrm{~h}$

$\rightarrow 1.5 \mathrm{~h}$

$\times 2 \mathrm{~h}$

$-3 \mathrm{~h}$

$-\approx \mathrm{h}$

$-7-6 \mathrm{~h}$

-.- $8 \mathrm{~h}$

$-10 \mathrm{~h}$

$-12 \mathrm{~h}$

\section{B}

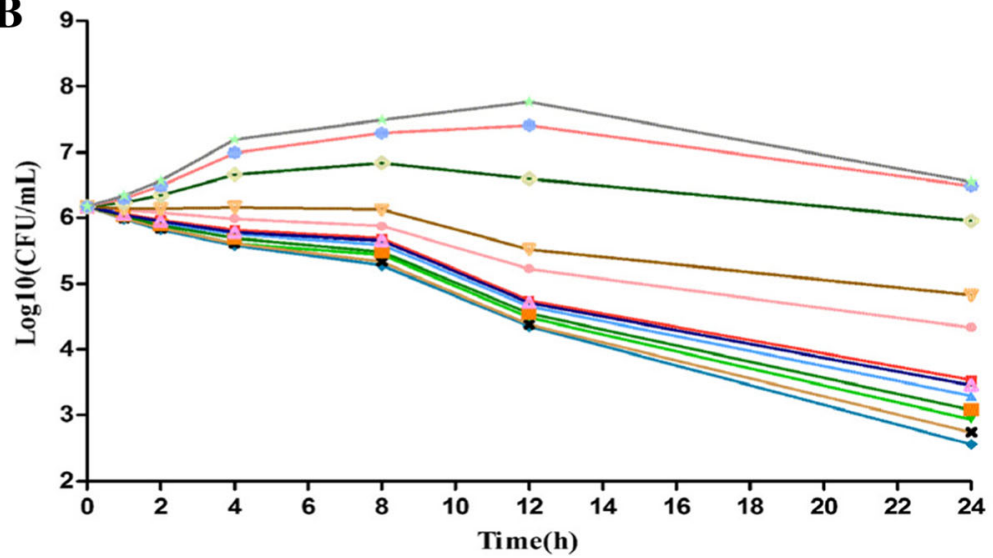

$\because 0.17 \mathrm{~h}$

$=0.33 \mathrm{~h}$

$\simeq 0.5 \mathrm{~h}$

$-1 \mathrm{~h}$

$\rightarrow 1.5 \mathrm{~h}$

$\times 2 \mathrm{~h}$

-m- $3 \mathrm{~h}$

$-4 \mathrm{~h}$

$-7 \mathrm{~h}$

- $8 \mathrm{~h}$

$\rightarrow 10 \mathrm{~h}$

$-12 \mathrm{~h}$

Fig. 2 The ex vivo antibacterial curve of tylosin against CVCC606 in serum from healthy pigs (a) and diseased pigs (b). The ex vivo antibacterial activity in serum was determined in samples harvested at pre-determined times $(0.17,0.33,0.5,1,2,3,4,6,8,10,12 \mathrm{~h}$ after tylosin IM dosing)

However, when the drug concentration was in the range of $0.25-1 \mu \mathrm{g} / \mathrm{mL}$, drug-resistance strains had selective growth and the growth of sensitive strains was inhibited. The drug-resistant strains do not appear when the concentrations of tylosin are higher than $1 \mu \mathrm{g} / \mathrm{mL}$.

\section{Discussion}

Dosage regimens of a drug were established according to the PD data and PK data from healthy and infected animals. However, the physiological status of the diseased animals should be considered when the dosage regimens were established. When animals were infected, body temperature, organization blood flow, capillary permeability, metabolic ability, plasma protein binding ratio etc. would be changed. The changes of the physiological status could influence the ADME, In diseased animals the Pharmacokinetics characteristics of the drug would be different from healthy animals [21]. So we studied the

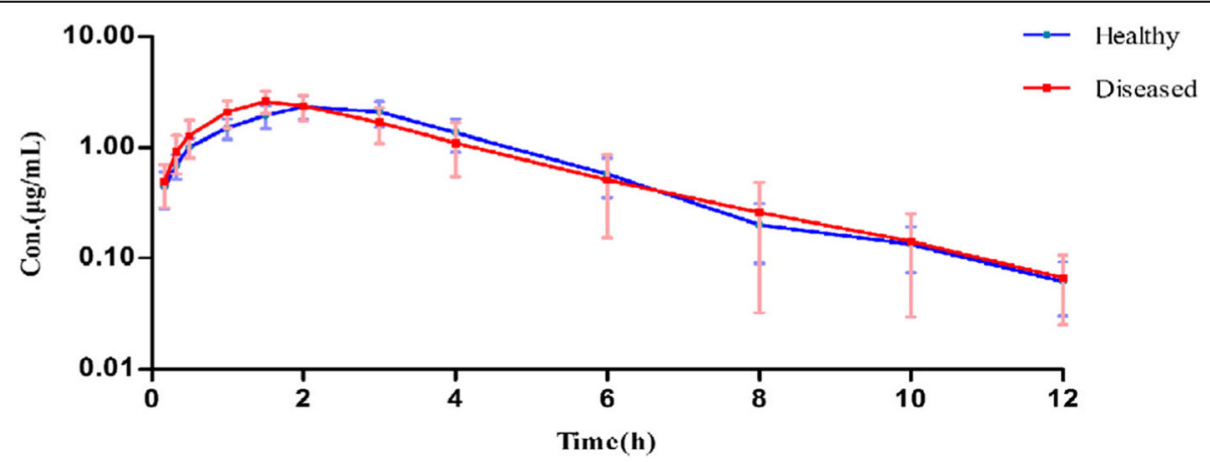

Fig. 3 Semi-logarithmic plot of serum concentrations of tylosin after IM administration at a dose rate of $10 \mathrm{mg} / \mathrm{kg}$ b.w. $(n=8)$ 
Table 2 Pharmacokinetic parameters of tylosin $(n=8)$ after $10 \mathrm{mg} / \mathrm{kg} \mathrm{IM}$ administration in pigs

\begin{tabular}{|c|c|c|c|}
\hline Parameter & Unit & Healthy (mean \pm SD) & Porcine streptococcosis (mean $\pm \mathrm{SD}$ ) \\
\hline $\mathrm{k}_{\mathrm{a}}$ & $1 / \mathrm{h}$ & $0.521 \pm 0.061$ & $0.759 \pm 0.372^{*}$ \\
\hline$k_{e}$ & $1 / \mathrm{h}$ & $0.518 \pm 0.060$ & $0.634 \pm 0.152^{*}$ \\
\hline AUC & $h \cdot \mu \mathrm{g} / \mathrm{mL}$ & $10.804 \pm 2.204$ & $10.297 \pm 3.458$ \\
\hline $\mathrm{T}_{1 / 2} \mathrm{k}_{\mathrm{a}}$ & h & $1.347 \pm 0.155$ & $1.060 \pm 0.383^{*}$ \\
\hline $\mathrm{T}_{1 / 2} \mathrm{k}_{\mathrm{e}}$ & h & $1.354 \pm 0.150$ & $1.152 \pm 0.293$ \\
\hline $\mathrm{T}_{\max }$ & h & $1.948 \pm 0.219$ & $1.578 \pm 0.487^{*}$ \\
\hline$C_{\max }$ & $\mu \mathrm{g} / \mathrm{mL}$ & $2.056 \pm 0.426$ & $2.372 \pm 0.376$ \\
\hline AUMC & $h \cdot h \cdot \mu g / m L$ & $36.169 \pm 6.570$ & $35.531 \pm 17.647$ \\
\hline MRT & h & $3.588 \pm 0.469$ & $3.353 \pm 0.694$ \\
\hline $\mathrm{CL} / \mathrm{F}$ & $\mathrm{mL} / \mathrm{min}$ & $15.944 \pm 2.946$ & $18.1326 \pm 7.265$ \\
\hline
\end{tabular}

Pharmacokinetics parameters and variables were calculated using a one-compartment model with first order input and output: $\mathrm{k}_{\mathrm{a}}$ is absorption rate constant; $\mathrm{k}_{\mathrm{e}}$ is elimination rate constant; $T_{1 / 2} k_{a}$ is absorption half-life; $T_{1 / 2} k_{e}$ is elimination half-life; $C_{\max }$ is maximum concentration in serum; $T_{\text {max }}$ is the time to achieve the maximum serum concentration; AUC is area under serum concentration-time curve; AUMC is area under the first moment curve; $\mathrm{MRT}$ is mean residence time; $\mathrm{CL} /$ $F$ is the body clearance corrected for bioavailability

*means significance difference $(P<0.05)$

Pharmacokinetics of tylosin in diseased pigs, and compared the character with healthy pigs. In this investigation, the experimental model of porcine streptococcosis was established through the subcutaneous inoculation [22]. Dosage regimen was established according to the PK data and PD data of tylosin, which were derived from diseased animals.

The PK of tylosin had already been investigated in goat, sheep, pigs, chickens [23] and camel [24] following intravenous(IV) and/or IM administration. In the present study, the result showed that tylosin fitted the one-compartmental open model in healthy pigs and diseased pigs in accordance with previous reports in different animals [25]. The absorption half-life of tylosin in diseased pigs was slightly shorter than that reported in healthy pigs $\left(\mathrm{T}_{1 / 2 \mathrm{ka}}=1.36 \mathrm{~h}\right)$ [26]. In our study the terminal half-life was shorter in both diseased $\left(\mathrm{T}_{1 / 2 \mathrm{ke}}=1.152 \mathrm{~h}\right)$ and healthy pigs $\left(\mathrm{T}_{1 / 2 \mathrm{ke}}=1.354 \mathrm{~h}\right)$ than previous investigations in pigs $\left(\mathrm{T}_{1 / 2 \mathrm{ke}}=3.01 \mathrm{~h}\right)$, cattle and buffaloes $(2.24$ and $2.4 \mathrm{~h}$, respectively) [27]. A higher $C_{\max }$ values were obtained in diseased pigs $(2.372 \mu \mathrm{g} / \mathrm{mL})$ than healthy pigs $(2.056 \mu \mathrm{g} /$ $\mathrm{mL}$ ), but both were lower than that found in previous data $\left(C_{\max }=2.71 \mu \mathrm{g} / \mathrm{mL}\right)$. This study showed that the time to reach the maximum concentration of tylosin in blood is short in diseased animals as compared to healthy pigs. In this study the PK parameters $T_{1 / 2 k a}$ and $T_{\max }$ were significantly lower in diseased pigs than healthy pigs. The results indicated that tylosin had a quicker absorption and elimination in infected pigs with S. suis, and tylosin reached the peak concentration earlier. Therefore, it had a great clinical significance that to formulate a dose schedule of tylosin against porcine streptococcosis.

The differences of the Pharmacokinetics of tylosin in healthy and diseased pigs may be due to the change of the physiological and biochemical indices, such as the change of body temperature, the decrease of the protein in plasma, the decline of plasma glue through pressure, anemia, liver dysfunction of acetylation and so on. The changes can influence the absorption, distribution and elimination of the drug in animal.

Table 3 In vivo PK-PD parameter of tylosin afer IM administration at a dose rate of $10 \mathrm{mg} / \mathrm{kg}(n=8)$

\begin{tabular}{llll}
\hline PK-PD parameter & Unit & Healthy Pigs Mean \pm SD & Infected Pigs Mean \pm SD \\
\hline AUC & $\mathrm{h} \cdot \mu \mathrm{g} / \mathrm{mL}$ & $10.804 \pm 2.204$ & $10.297 \pm 3.458$ \\
$C_{\max }$ & $\mu \mathrm{g} / \mathrm{mL}$ & $2.225 \pm 0.485$ & $2.442 \pm 0.389$ \\
$\mathrm{MIC}$ & $\mu \mathrm{g} / \mathrm{mL}$ & 0.250 & 0.250 \\
$\mathrm{MBC}$ & $\mu \mathrm{g} / \mathrm{mL}$ & 1.000 & 1.000 \\
$\mathrm{AUC}_{24 \mathrm{~h}} / \mathrm{MIC}$ & $\mathrm{h}$ & $43.216 \pm 8.816$ & $41.188 \pm 13.832$ \\
$\mathrm{AUC}_{24 \mathrm{~h}} / \mathrm{MBC}$ & $\mathrm{h}$ & $10.804 \pm 2.204$ & $10.297 \pm 3.458$ \\
$C_{\max } / \mathrm{MIC}$ & - & $8.900 \pm 1.940$ & $9.768 \pm 1.556$ \\
$C_{\max } / \mathrm{MBC}$ & - & $2.225 \pm 0.485$ & $2.442 \pm 0.389$ \\
$T_{>M I C}$ & $\mathrm{~h}$ & $8.863 \pm 0.914$ & $7.568 \pm 2.220$ \\
$T_{>M B C}$ & $\mathrm{~h}$ & $4.712 \pm 0.756$ & $4.327 \pm 1.433$ \\
\hline
\end{tabular}


Table 4 Ex vivo $\mathrm{AUC}_{24 \mathrm{~h}} / \mathrm{MIC}$ value (mean $\pm \mathrm{SD}, \mathrm{n}=8$ ) of tylosin after IM administration at a dose rate of $10 \mathrm{mg} / \mathrm{kg}$

\begin{tabular}{|c|c|c|c|c|}
\hline \multirow[t]{2}{*}{ Time(h) } & \multicolumn{2}{|l|}{ Healthy Pigs } & \multicolumn{2}{|l|}{ Infected Pigs } \\
\hline & $\mathrm{AUC}_{24 \mathrm{~h}} / \mathrm{MIC}(\mathrm{h})($ Mean $\pm \mathrm{SD})$ & E & $\mathrm{AUC}_{24 \mathrm{~h}} / \mathrm{MIC}(\mathrm{h})($ Mean $\pm \mathrm{SD})$ & E \\
\hline 0 & 0 & 3.23 & 0 & 3.345 \\
\hline 0.17 & $10.587 \pm 3.835$ & -1.199 & $11.832 \pm 4.979$ & -1.833 \\
\hline 0.33 & $16.617 \pm 4.260$ & -1.895 & $22.185 \pm 8.413$ & -2.633 \\
\hline 0.5 & $24.177 \pm 5.010$ & -2.614 & $30.768 \pm 11.325$ & -2.879 \\
\hline 1 & $35.904 \pm 7.518$ & -2.932 & $49.743 \pm 13.588$ & -3.234 \\
\hline 1.5 & $46.572 \pm 11.173$ & -3.085 & $62.532 \pm 14.423$ & -3.620 \\
\hline 2 & $56.271 \pm 13.789$ & -3.488 & $56.343 \pm 14.827$ & -3.431 \\
\hline 3 & $49.797 \pm 13.062$ & -3.329 & $40.374 \pm 14.276$ & -3.091 \\
\hline 4 & $32.676 \pm 10.897$ & -2.800 & $26.565 \pm 13.558$ & -2.716 \\
\hline 6 & $13.854 \pm 5.403$ & -1.462 & $12.162 \pm 8.473$ & -1.338 \\
\hline 8 & $4.794 \pm 2.640$ & 0.587 & $6.189 \pm 5.428$ & -0.212 \\
\hline 10 & $2.712 \pm 1.409$ & 1.093 & $3.393 \pm 2.693$ & 0.319 \\
\hline 12 & $1.452 \pm 0.750$ & 1.184 & $1.578 \pm 0.979$ & 0.382 \\
\hline
\end{tabular}

The determination of MIC is the lowest concentration that the drug can inhibit the growth of microorganism in an artificial medium, such as in agar and in broth. The composition of the artificial medium is different from serum in several respects, such as the electrolyte concentrations (calcium and magnesium), $\mathrm{pH}$ and protein concentration. Consequently, The MIC value determined in broth or agar can't take the place of those determined in serum. For example, Pridmore determined the range of MICs for Tiamulin against 4 strains of Actinobacillus pleuropneumoniae in culture and serum were $12-24 \mu \mathrm{g} / \mathrm{mL}, 14-24 \mu \mathrm{g} / \mathrm{mL}, 12-32 \mu \mathrm{g} / \mathrm{mL}$ and $12-24 \mu \mathrm{g} / \mathrm{mL}$, respectively [28], showed that tiamulin had different antibacterial effect in culture and in serum. However, in this investigation, the MIC of tylosin against $S$. suis strains in $\mathrm{MH}$ broth and serum were the same $0.25 \mu \mathrm{g} / \mathrm{mL}$.

The ex vivo antimicrobial data were generated into Sigmoid $E_{\max }$ equation, indicated that tylosin could

Table 5 The result of the sigmoid $E_{\max }$ model

\begin{tabular}{lll}
\hline Parameter & Healthy & porcine streptococcosis \\
\hline$E_{\max }$ & 3.230 & 3.345 \\
$\mathrm{EC}_{50}$ & 11.171 & 12.233 \\
$\mathrm{E}_{0}$ & -3.488 & -3.620 \\
$\mathrm{~N}$ & 1.707 & 1.849 \\
$E_{\max }-E_{0}$ & 6.718 & 6.965 \\
$\mathrm{AUC}_{24} \mathrm{~h} / \mathrm{MIC}$ for bacteriostatic action & 10.679 & 11.736 \\
AUC $_{24} \mathrm{~h} / \mathrm{MIC}$ for bactericidal action & 49.665 & 43.032
\end{tabular}

$E_{\max }$ is maximam difference in $\log _{10}$ of bacterial number of sample incubated with drug, $\mathrm{EC}_{50}$ is the PK-PD parameter of drug that produce $50 \%$ of the maximal antibacterial effect, $E_{0}$ is the difference after $24 \mathrm{~h}$ incubation in $\log _{10}$ of number of bacteria in control samples, $\mathrm{N}$ is the HILL coefficient which discribes the steepness of the parameter-effect curve achieve the bacteriostatic and bactericidal action, but couldn't achieve the elimination action. The reason of this phenomenon was that tylosin is a bacteriostatic drug, which inhibits growth of the organism and requires the aid of defense system to clear the infecting microorganisms of tissues. For a bacteriostatic drug, when drug levels are lower than MIC, the decline of bacterial count is mainly the result of the host defense. But the rate and degree of bacteriostatic drugs against microorganisms is weaker than bactericidal drugs. Aliabadi established PK-PD model of danofloxacin against Mannheimis haemolytica, and the $E_{\max }$ of danofloxacin was 4.967, which could achieve bactericidal action and elimination action [29]. For bactericidal drugs, they showed an obvious effect of sterilization when the concentration is above MBC after animals were administrated, and they showed a bacteriostatic effect when the concentration is below MBC.

Macrolides is a kind of time-dependent drug, but every drug has its own characteristic. The conventional macrolides (e.g. erythromycin) are classical time-dependent drugs without PAE [30]. However, a few of them (e.g. azithromycin) express time-dependent and weak concentration-dependent with prolonged PAE. So one parameter $\left(\mathrm{T}_{>\mathrm{MIC}}\right)$ can't describe the antibacterial activity of macrolides.

Tylosin killed S. suis by a time-dependent and weak concentration-dependent characteristic with prolonged PAE, the antimicrobial effect was strengthened with the extension of time or the increase of concentration. The PAE of tylosin against $S$. suis was prolonged, the PAE was $3.43 \mathrm{~h}$ when S. suis was exposed in 2MIC for $2 \mathrm{~h}$, and $4.21 \mathrm{~h}$ when was expose in $4 \mathrm{MIC}$ for $2 \mathrm{~h}$. So the the best PK-PD index responsible for the efficacy of of 

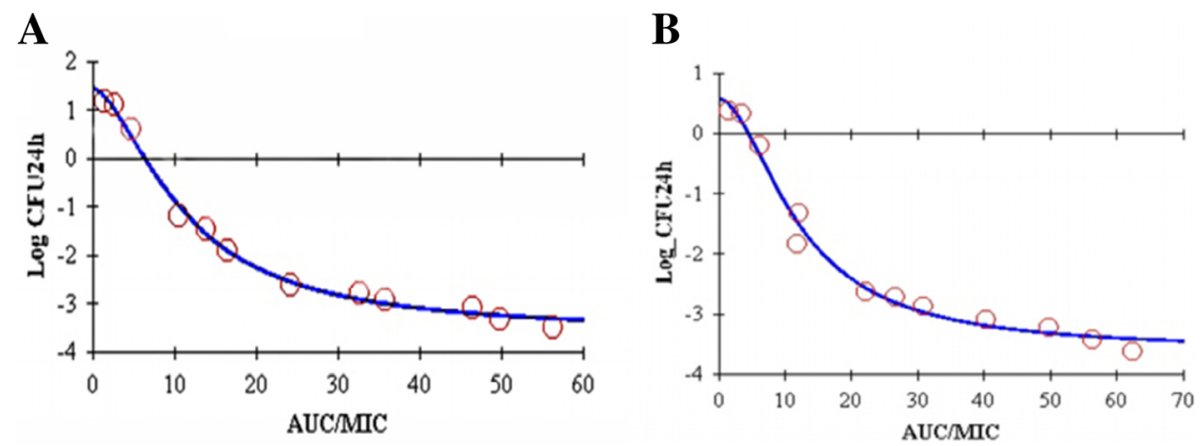

Fig. 4 Sigmoid Emax relationship for bacterial count vs. ex vivo AUC/MIC in serum from healthy pigs(a) and diseased pigs(b)

tylosin against $S$. suis was AUC/MIC according to the bacterial killing curve and PAE.

It is necessary to consider whether the differences in ex vivo conditions used in this investigation and those occurring clinically in diseased animals may be associated with differences in tylosin efficacy. First, the role of host defense mechanisms must be regard as a primary consideration in vivo. For the healthy animal the immune system is competent, so the body's defense mechanisms playing an auxiliary function and will exert synergistic effect with administered drug. However, host defense mechanisms are not taken into consideration under in vitro conditions. A second difference is that a single strain was used in ex vivo investigation, but in vivo study, several strains are in the body at the same time. The predictions of dosage treating with this organism are likely to act on other strains of the same organism, but this can't be assumed for acting on other species of bacteria. Thirdly, under ex vivo condition, organisms are exposed to a fixed drug concentration for a fixed time to carry out the assessment of bacterial count made at $1,2,4,8,12$ and $24 \mathrm{~h}$. However, under in vivo conditions, the concentrations of the drug first raise to a peak and then decrease, the concentration will keep changing unless the drug is infused IV at a rate such that the serum concentration will maintain constant (the infusion using a precise rate can ensure that administration and elimination rates are exactly balanced).

The PK-PD indices derived from serum were integrated using the present data, the parameter of AUC/ MIC in serum relates to the biophase, which is with regard to bacteria in plasma and tissues. The data derived from serum are more relevant to the host conditions

Table 6 AUC/MIC parameter values and dosage achieving different antibacterial effect based on infected pigs

\begin{tabular}{lll}
\hline Antibacterial effect & AUC/MIC Values & Dosage $(\mathrm{mg} / \mathrm{kg})$ \\
\hline Bacteriostatic & 11.736 & 5.320 \\
Bactericidal & 43.032 & 19.507 \\
\hline
\end{tabular}

than in vitro investigation of using artificial media such as MHB. The growth curve of the bacteria was also determined in serum, which is more appropriate than in vitro PD parameters (such as MIC, MBC and the killing curve), to describe the antibacterial activity of tylosin. $\mathrm{MIC}$ and $\mathrm{MBC}$ are indirect or surrogate maker, but they are essential because direct indices of antimicrobial activity are not available.

The rationale of using the AUC/MIC to calculate the rational dosage is that Pharmacokinetics of the drug in vivo expressing a linear kinetic character, the rate of the drug's transformation and elimination are dose-independent and concentration-independent. There is positive correlation between AUC and/or the concentration of the drug in plasma or serum. According to our PK and PD parameters in this study, the optimal single dose required to reach bacteriostatic, bactericidal activity were 5.320 and $19.507 \mathrm{mg} / \mathrm{kg}$, respectively. What's more, tylosin was a growing bacteriostatic drug which exerted its function by inhibiting protein synthesis of the organism, and could reach bacteriostatic and bactericidal action. The dose regimen was depended on bacterial population and PK data obtained from diseased animal, this might be more

Table $\mathbf{7}$ The growth of resistant strains after exposed to different concentrations of tylosin

\begin{tabular}{lllllll}
\hline $\begin{array}{l}\text { Concentrations } \\
(\mu \mathrm{g} / \mathrm{mL})\end{array}$ & \multicolumn{7}{l}{ Time $(\mathrm{h})$} & & & \\
\cline { 2 - 7 } & 0 & 2 & 4 & 8 & 12 & 24 \\
\hline 0 & + & + & + & ++ & ++ & + \\
0.125 & + & + & + & + & ++ & ++ \\
0.25 & + & + & + & + & ++ & ++ \\
0.5 & + & + & + & ++ & ++ & + \\
1 & + & + & + & + & + & + \\
2 & + & + & + & + & $\mathrm{N}$ & $\mathrm{N}$ \\
4 & + & + & $\mathrm{N}$ & $\mathrm{N}$ & $\mathrm{N}$ & $\mathrm{N}$ \\
8 & + & + & $\mathrm{N}$ & $\mathrm{N}$ & $\mathrm{N}$ & $\mathrm{N}$ \\
\hline
\end{tabular}

$\mathrm{N}$, colony number below $10 \mathrm{cfu} / \mathrm{mL} ;+$, colony number between 10 and $1000 \mathrm{cfu} / \mathrm{mL} ;++$, colony number beyond $1000 \mathrm{cfu} / \mathrm{mL}$ 
appropriate to take into account the conditions of diseased pigs in clinical application.

According to the theory of MSW, when the concentration of drug is below MIC, the growth of bacteria is not inhibited, and drug-resistant mutant strains are not dominant in the growth of the whole bacteria. When the concentration of drug is in the range of MIC-MPC, the sensitive bacteria are inhibited and the drug-resistant strains can grow selectively, thus bacterial resistance develops. Assessment of bacteria resistance could be performed by PK-PD model theory and MSW theory. Based on our results, the times that tylosin concentrations in pigs maintained above $1 \mu \mathrm{g} / \mathrm{mL}\left(\mathrm{T}_{>\mathrm{MPC}}\right)$ were $4.712 \mathrm{~h}$ and $4.327 \mathrm{~h}$ for healthy pigs and $S$. suis infected pigs, and $C_{\max }$ were $2.056 \mu \mathrm{g} / \mathrm{mL}$ and $2.372 \mu \mathrm{g} / \mathrm{mL}$, respectively. And the times that tylosin concentrations in pigs from $1 \mu \mathrm{g} / \mathrm{mL}$ to $0.25 \mu \mathrm{g} / \mathrm{mL}\left(\mathrm{T}_{\mathrm{MSW}}\right)$ were $3.773 \mathrm{~h}$ and $2.997 \mathrm{~h}$ for healthy pigs and S. suis infected pigs, respectively. The PAE that $S$. suis were exposed in $1 \mu \mathrm{g} / \mathrm{mL}$ tylosin solution for $2 \mathrm{~h}$ was $4.21 \mathrm{~h}$, So the bacteria were inhibited when the tylosin concentration was in MSW, and no selective growth of bacteria were produced, therefore no resistance emerge after IM administration at a dose rate of $10 \mathrm{mg} / \mathrm{mL}$.

\section{Conclusions}

According to our investigation the tylosin had the same antibacterial activity in both serum and $\mathrm{MH}$ broth, and showed an obvious time-dependent and weak concentration-dependent antimicrobial activity, therefore the best PK/PD surrogate marker was AUC/MIC. Porcine streptococcosis for the dosage regimen, the calculation of dosage for prevention and treatment based on the data of diseased pigs, and it might be more practical to apply clinically for tylosin against $S$. suis. The dosage regimen of $5.320-19.507 \mathrm{mg} / \mathrm{kg}$ b.w. for every $24 \mathrm{~h}$ should be adequate for the treatment of tylosin against $S$. suis in clinical practice.

\section{Methods}

\section{Antimicrobial}

Tylosin standard was purchased from Dr. Ehrenstorfer Germany for in vitro experiments (Det. Purity 98\%; Lot Number 17895600). Tylosin injectable solution $(50 \mathrm{mg} /$ $\mathrm{mL}$ ) was compounded before experiment; each milliliter contains $50 \mathrm{mg}$ of tylosin activity (as tylosin base) in $50 \%$ propylene glycol with $4 \%$ benzyl alcohol and water for injection.

\section{Bacteria}

S. suis CVCC606 (pig isolate, serotype 2) was purchased from Chinese veterinary culture collection. The strain was grown freshly from beads, previously store at $-70^{\circ}$ $\mathrm{C}$, on tryptone soya blood agar.

\section{Animals}

The study was carried out on 16 pigs (Duroc $\times$ Large White $\times$ Landrace pigs) of either sex which were 6 weeks old having average weight of $16 \pm 2 \mathrm{~kg}$. The animals were acclimatized for a period of 1 week before experiment. Animals were housed in two separated concrete floor rooms, fed twice daily and watered ad libitum. The Euthanasia procedure is carried by pentobarbital sodium with IV administration when study was finished. The experimental procedures involving animals in the study were approved by the Animal Ethics Committee of Huazhong Agricultural University and the Animal Care Center, Hubei Science and Technology Agency.

After acclimatization period the animals were divided randomly into Group A and B. Group A was inoculated subcutaneously with $1 \mathrm{~mL}$ of $1.2 \times 10^{9} \mathrm{cfu} / \mathrm{mL}$ S. suis to establish the disease model. The animals in group B were kept as control.

After the inoculation, further experiment was started when streptococcosis symptoms like high temperature, loss of appetite, spiritual malaise, breathing rate increased, coughed, corneal flushed, joints swelling, CNS signs were observed.

\section{In vitro pharmacodynamic of tylosin against Streptococcus suis CVCC606}

\section{Determination of MIC, MBC in broth and serum}

MIC (Minimal Inhibitory Concentration) was defined as the minimum concentration of drugs where no visible growth of bacteria was observed. The determination was performed by microbroth dilution method according to CLSI (Clinical and Laboratory Standards Institute, formerly NCCLS) document VET01 A4, 2013. A logarithmic phase culture of each bacterial strain was diluted with proper broth in order to obtain a density of $1 \times$ $10^{6} \mathrm{cfu} / \mathrm{mL}$.

Tylosin solutions containing a $128 \mu \mathrm{g} / \mathrm{mL}$ of Tylosin were added to $0.1 \mathrm{~mL}$ of MHB or serum (obtained from the control animals). Serial dilutions were prepared in broth or serum with concentrations ranging between $64 \mu \mathrm{g} / \mathrm{mL}$ and $0.0625 \mu \mathrm{g} / \mathrm{mL}$, and dilutions were prepared in 96-wells microplate. Plates were inoculated with $0.1 \mathrm{~mL}$ of culture to give a final concentration of approximately $5 \times 10^{5} \mathrm{cfu} / \mathrm{mL}$. Plates were incubated at $37{ }^{\circ} \mathrm{C}$ for $18-24 \mathrm{~h}$, then shaken to mix the contents. After the tylosin-inoculum mixture was mixed, plates were incubated at $37{ }^{\circ} \mathrm{C}$ for $18 \mathrm{~h}$.

An aliquot of $100 \mu \mathrm{L}$ from each tube was subcultured on TSA, the plates were incubated at $37{ }^{\circ} \mathrm{C}$ overnight, and the colonies were counted, the limit of the detection was $10 \mathrm{cfu} / \mathrm{mL}$. MIC was determined as the lowest concentration at which bacteria numbers remained at the original inoculums level. MBC (Minimal Bactericidal Concentration) is the lowest concentration where 
bacteria numbers were reduced by $99.9 \%$ and was determined according to the CLSI document M26-AE [31].

\section{Determination of MPC}

The mutant prevention concentration (MPC) was determined by agar method according to the procedure of Blondeau [32]. MPC was defined as the lowest drug concentration that prevented bacterial colony formation from a culture containing $>10^{10}$ bacteria. The $S$. suis were concentrated to $>10^{10} \mathrm{cfu} / \mathrm{mL}$ bacteria. $0.1 \mathrm{~mL}$ of the bacterial suspension (final concentration of $10^{10} \mathrm{cfu} /$ $\mathrm{mL}$ ) was cultured on $\mathrm{MH}$ Agar plates containing concentrations of tylosin in a series of two-fold dilutions, beginning with a concentration equal of the MIC. Inoculated plates were incubated for $72 \mathrm{~h}$, and colonies were counted every after $24 \mathrm{~h}$. All MPC determinations were performed in duplicate.

\section{Time-kill curve}

The time-kill curves were established by making different concentrations of tylosin ranging from $1 / 4 \mathrm{MIC}$ to 32 MIC before bacterial inoculation of S. suis $\left(10^{6} \mathrm{cfu} /\right.$ $\mathrm{mL})$. Growth of bacteria was checked with control. The tubes containing cultures of bacteria and different concentrations of drugs were incubated under aerobic conditions at $37{ }^{\circ} \mathrm{C}$ for $24 \mathrm{~h}$. The Bacterial count $(\mathrm{cfu} / \mathrm{mL})$ was checked after 1, 2, 4, 8, 12 and $24 \mathrm{~h}$ incubation, by re-seeding aliquots on agar medium in the absence of tylosin.

\section{Determination of PAE}

The post-antibiotic effect (PAE) was determined after removal of drug by dilution method. The $S$. suis were incubated with $1 \mathrm{MIC}, 2 \mathrm{MIC}$ and $4 \mathrm{MIC}$ of drug. After 1 and $2 \mathrm{~h}$ incubation the drug was eliminated by several times centrifugation and wash with fresh medium. Growth curves were determined for $24 \mathrm{~h}$. The PAE was calculated from the regrowth curves using the equation: $\mathrm{PAE}=\mathrm{T}-\mathrm{C}$. In which $\mathrm{T}$ is the time required for the bacterial population in the test culture to increase $1 \log _{10}$ after dilution, and $\mathrm{C}$ is the corresponding time for the control culture.

\section{Pharmacokinetics of tylosin in pigs \\ Dose and sampling}

A pharmacokinetic study was carried out in pigs. Each pigs received tylosin at a dose of $10 \mathrm{mg} / \mathrm{kg}$ of body weight by IM administration. Blood samples $(2 \mathrm{~mL})$ were collected at $0,0.17,0.33,0.5,1,1.5,2,3,4,6,8,10$ and $12 \mathrm{~h}$ after tylosin administration for determination of tylosin concentration and ex vivo antibacterial activity. The samples were collected without anticoagulant, and then kept at a room temperature for $2 \mathrm{~h}$ in dark. Blood was centrifuged at $3000 \mathrm{r} / \mathrm{min}$ for $10 \mathrm{~min}$ to obtain serum, and serum samples were protected from light and stored at $-20{ }^{\circ} \mathrm{C}$ prior to the analysis.

\section{HPLC analysis of tylosin in serum}

Tylosin concentrations in pig serum were determined by a Waters 2695 series HPLC and a Waters 2487 UV detector set at a wavelength of $286 \mathrm{~nm}$. A volume of $0.5 \mathrm{~mL}$ of serum was added to a $10 \mathrm{~mL}$ tube, then added $4 \mathrm{~mL}$ acetonitrile to precipitate proteins. After centrifugation at $4000 \mathrm{r} / \mathrm{min}$ for $10 \mathrm{~min}$, the supernatant was collected into a tube and evaporated with a nitrogen instrument. The dry extracts dissolved in $200 \mu \mathrm{L}$ of the mobile phase were injected into the chromatographic system after filtered. Calibration curves were prepared after adding tylosin into blank samples before they were extracted by the method described above. HPLC was performed in a reverse-phase column C18 (4.6× $200 \mathrm{~mm}, 5 \mu \mathrm{m}$ particle size). The mobile phase was acetonitrile: $0.1 \mathrm{M}$ ammonium formate at a flow rate of $1.0 \mathrm{~mL} / \mathrm{min}$. The mean recovery of tylosin from serum samples was $93 \pm 4 \%$ across a series of concentrations investigated. The limits of detection (LOD) were calculated on a signal to noise ratio of 3 , and the value was $30 \mathrm{ng} / \mathrm{mL}$, and the limit of quantification (LOQ) at signal to noise ratio of 10 was $50 \mathrm{ng} / \mathrm{mL}$. The accuracy and precision of method was investigated with standard serum samples containing series of tylosin concentrations, and the inter-assay and intra-assay coefficients of variation were less than $10 \%$, respectively. The specificity of the method above was suitable for these target substances, and there was also no endogenous interference on chromatograms.

\section{PK analysis}

Pharmacokinetic parameters and the concentration-time data of tylosin in serum from individual pigs were analyzed using the Winnonlin programme (Pharsight Corporation, Mountain View, CA, version 5.2, USA). Serum data were submitted to compartmental analysis using non-linear least squares regression. Data for serum were also subjected to non-compartmental analysis using the statistical moment approach and Winnonlin programme. The linear trapezoidal rule was used to calculate the area under concentration-time curve (AUC) and area under the first moment curve (AUMC). The mean residence time (MRT) was determined as AUMC/AUC.

\section{Statistical analysis}

All data were presented as means \pm SD. For these parameters and variables, the SDs for arithmetic means had been employed to give an indication of the variation in data. For PK variables, the statistical differences between healthy pigs and S.suis infected pigs data were assessed using the significant difference method with SPSS 
software package. Chi-squared tests were applied to determine whether there were statistical differences in the antimicrobial resistance. A $P$-value $<0.05$ was considered to indicate statistical significance in the results.

\section{Ex vivo antibacterial activity of tylosin}

S. suis CVCC606 was grown freshly on TSA, three to five colonies were selected to inoculate in $9 \mathrm{~mL} \mathrm{MHB}$ and then the tubes were placed at $37{ }^{\circ} \mathrm{C}$ in incubator overnight. Serum samples were collected at $0,0.17,0.33$, $0.5,1,1.5,2,3,4,6,8,10$ and $12 \mathrm{~h}$ post administration of drug from healthy and diseased pigs. A $5 \mu \mathrm{L}$ of bacterial culture in stationary phase was added to $0.5 \mathrm{~mL}$ serum, giving a final inoculum of $1 \times 10^{6} \mathrm{cfu} / \mathrm{mL}$. The tubes containing bacteria and serum were incubated at $37{ }^{\circ} \mathrm{C}$ and bacterial counts were determined by plate count method at 1, 2, 4, 8, 12 and $24 \mathrm{~h}$. The limit of detection was $10 \mathrm{cfu} / \mathrm{mL}$.

\section{PK and PD integration and modeling}

By using in vitro MIC and in vivo PK parameters, the surrogate markers of antimicrobial activity (AUC/MIC) were determined for serum after IM dosing of tylosin for each pigs. Results were expressed as means \pm SD.

The relationship between the ex vivo $\mathrm{AUC}_{24} / \mathrm{MIC}$ and $\log _{10}$ difference between the initial bacterial count (in number of per $\mathrm{mL}$ ) and the bacterial count after $24 \mathrm{~h}$ of incubation was established for serum by using the Sigmoid $E_{\max }$ model, this model was described by the following equation:

$$
E=E_{0}-\frac{\left(E_{\max }-E_{0}\right) \cdot C_{e}^{N}}{E C_{50}{ }^{N}+C_{e}^{N}}
$$

In which $E$ is the antibacterial effect measured as the change in the bacterial count $\left(\log _{10} \mathrm{cfu} / \mathrm{mL}\right)$ in the serum sample after $24 \mathrm{~h}$ of incubation compared to the initial $\log _{10} \mathrm{cfu} / \mathrm{mL}, E_{\max }$ is the maximum antibacterial effect determined as difference in $\log _{10} \mathrm{cfu} / \mathrm{mL}$ in sample incubated between $0 \mathrm{~h}$ and $24 \mathrm{~h}, \mathrm{E}_{0}$ is the change in $\log _{10}$ difference in bacterial count in the control sample between 0 and $24 \mathrm{~h}$ of incubation; $\mathrm{EC}_{50}$ is the $\mathrm{AUC} / \mathrm{MIC}$ value producing $50 \%$ of the maximum antibacterial effect; $\mathrm{C}_{\mathrm{e}}$ is the AUC/MIC in the effect compartment (the ex vivo site, that is serum); and $\mathrm{N}$ is the Hill coefficient, which describes the steepness of the AUC/MIC-effect curve.

Three levels of antibacterial effect of tylosin were quantified from the sigmoid $E_{\max }$ equation by determining $\mathrm{AUC} / \mathrm{MIC}$ required for bacteriostatic action (no change in bacterial counts after $24 \mathrm{~h}$ incubation, $\mathrm{E}=0$ ); bactericidal action (a 99.9\% reduction in bacterial count, $\mathrm{E}=-3$ ), and bacterial elimination (the lowest AUC/MIC that produce a $99.99 \%$ reduction in the count, $\mathrm{E}=-4$ ) in each of the serum.

\section{Dosage regimen and resistance risk assessment}

The calculation of the potential optimal dosage could be performed using this equation:

$$
\text { Dose }=\frac{\left(A U C_{24} / M I C\right) \times M I C \times C L}{f u \times F}
$$

In which MIC is minimum inhibitory concentration in this study; AUC/MIC is the target end point for optimal efficacy; CL is clearance; fu is the free fraction of tylosin. In this study, tylosin is a moderately bound by serum proteins (40\%) [33]. F is bioavailability.

For risk assessment different concentration of tylosin $(0,0.125,0.25,0.5,1,2,4,8 \mu \mathrm{g} / \mathrm{mL})$ were added to each tubes containing bacterial suspension $10^{10} \mathrm{cfu} / \mathrm{mL}$. the colony were checked after $0,2,4,12,24 \mathrm{~h}$ incubation, Any plate containing 100 cfus or less was not considered to be a drug-induced mutation.

\section{Abbreviations}

AUC: Area under the curve; AUC/MIC: The area under the curve divided by the MIC; AUMC: The area under the first moment curve; CFU: Colony forming unit; CLSI: Clinical and Laboratory Standards Institute; $C_{\max }$ : Peak concentration; $\mathrm{C}_{\max } / \mathrm{MIC}$ : The maximum concentration divided by MIC; HPLC: High performance liquid chromatography; LOD: The limits of detection; LOQ: The limit of quantification; MBC: The minimal bactericidal concentration; MH broth: Mueller hinton broth; MIC: The minimum inhibitory concentration; MPC: The mutant prevention concentration; MRT: The mean residence time; MSW: Mutation selection window; PAE: The post-antibiotic effect; PK/PD: Pharmacokinetics/pharmacodynamic; S. suis: Streptococcus suis; $\mathrm{T}_{>\mathrm{MI}}$ : The time that tylosin concentrations were above the minimum inhibitory concentration; $T_{\max }$ : Time to reach $C_{\max }$ TSA: Tryptone soybean agar

\section{Acknowledgments}

Not applicable.

\section{Funding}

This research was partly financially supported by the National key research and development program (2016YFD0501310), and the fundamental research funds for the Central Universities (2662017PY081). The funding body had no role in the design of the study, collection, analysis, and interpretation of data and in writing the manuscript.

\section{Availability of data and materials}

The data and material used and analyzed during the current study are available from the corresponding author on reasonable request.

\section{Authors' contributions}

ZY and LH, YW were responsible for the study design and coordination and were involved in drafting the manuscript. $\mathrm{HZ}$ carried out the pharmacodynamic determination and in vitro time kill curve studies, ML and IA participated in the data analysis and revising the manuscript. All authors read and approved the final manuscript.

\section{Ethics approval and consent to participate}

This study was approved by the Animal Ethics Committee of Huazhong Agricultural University and the Animal Care Center, Hubei Science and Technology Agency. 


\section{Competing interests}

The authors declare that the research was conducted in the absence of any commercial or financial relationships that could be construed as a potential conflict of interest.

\section{Publisher's Note}

Springer Nature remains neutral with regard to jurisdictional claims in published maps and institutional affiliations.

\section{Author details}

'MOA Laboratory for Risk Assessment of Quality and Safety of Livestock and Poultry Products, Wuhan, Hubei, China. ${ }^{2}$ National Reference Laboratory of Veterinary Drug Residues (HZAU) and MOA Key Laboratory for the Detection of Veterinary Drug Residues in Foods, Wuhan, Hubei, China. ${ }^{3}$ Huazhong Agricultural University, Wuhan, Hubei, China. ${ }^{4}$ Department of Animal Health The University of Agriculture Peshawar, Peshawar 25130, Pakistan.

Received: 26 January 2018 Accepted: 10 October 2018

Published online: 24 October 2018

\section{References}

1. Rajahram GS, Hameed AA, Menon J, William T, Tambyah PA, Yeo TW. Case report: two human Streptococcus suis infections in Borneo, Sabah, Malaysia. BMC Infect Dis. 2017;17(188):1-3.

2. Seitz M, Valentin-Weigand P, Willenborg J. Use of antibiotics and antimicrobial resistance in veterinary medicine as exemplified by the swine pathogen Streptococcus suis. Curr Top Microbiol Immunol. 2016;398:103-21.

3. Huong VTL, Ha N, Huyb NT, Horby P, Nghia HDT, Thiem VD, et al. Epidemiology, clinical manifestations, and outcomes of Streptococcus suis infection in humans. Emerg Infect Dis. 2014;20(7):1105-14.

4. Athey TBT, Teatero S, Takamatsu D, Wasserscheid J, Dewar K, Gottschalk M, et al. Population structure and antimicrobial resistance profiles of Streptococcus suis serotype 2 sequence type 25 strains. PLoS One. 2016; 11(3):1-17.

5. Costa ATR, Lobato FCF, Abreu VLV, Assis RA, Reis R, Uzal FA. Serotyping and evaluation of the virulence in mice of Streptococcus suis strains isolated from diseased pigs. Rev Inst Med Trop Sao Paulo. 2005;47(2):113-5.

6. Goyette-Desjardins G, Auger JP, Xu J, Segura M, Gottschalk M. Streptococcus suis, an important pig pathogen and emerging zoonotic agent-an update on the worldwide distribution based on serotyping and sequence typing. Emerg Microbes Infect. 2014;3:6.

7. Segura M, Fittipaldi N, Calzas C, Gottschalk M. Critical Streptococcus suis virulence factors: are they all really critical? Trends Microbiol. 2017:25(7):585-99.

8. Normile D. Infectious diseases. WHO probes deadliness of China's pig-borne disease. Science (New York). 2005;309(5739):1308-9.

9. Princivalli MS, Palmieri C, Magi G, Vignaroli C, Manzin A, Camporese A, et al. Genetic diversity of Streptococcus suis clinical isolates from pigs and humans in Italy (2003-2007). Euro Surveill. 2009;14(33):15-21.

10. Avci T, Elmas M. Milk and blood pharmacokinetics of tylosin and tilmicosin following parenteral administrations to cows. Sci World J. 2014. https://doi. org/10.1155/2014/869096.

11. Stone JJ, Clay SA, Zhu Z, Wong KL, Porath LR, Spellman GM. Effect of antimicrobial compounds tylosin and chlortetracycline during batch anaerobic swine manure digestion. Water Res. 2009:43(18):4740-50.

12. Ji LW, Dong $L L$, Ji H, Feng XW, Li D, Ding RL, et al. Comparative pharmacokinetics and bioavailability of tylosin tartrate and tylosin phosphate after a single oral and i.v. administration in chickens. J Vet Pharmacol Ther. 2014:37(3):312-5.

13. Couper A, Cromie L, Neeve S, Pommier P, Keita A, Pagot E. (2006). Treatment of pneumonia in pigs with long-acting injectable tylosin. Vet Rec. 2006;159(24):805-7.

14. Munoz R, Cornejo J, Maddaleno A, Araya-Jordan C, Iraguen D, Pizarro N, et al. Withdrawal times of oxytetracycline and tylosin in eggs of laying hens after oral administration. J Food Prot. 2014;77(6):1017-21.

15. Devreese M, Osselaere A, Goossens J, Vandenbroucke V, De Baere S, De Backer $P$, et al. Interaction between tylosin and bentonite clay from a pharmacokinetic perspective. Vet J. 2012;194(3):437-9.

16. Atef $M$, Ramadan A, Darwish AS, Fahim AMM. Effect of albendazole administration on pharmacokinetic aspects of tylosin in lactating goats. Drug Metab Lett. 2009;3(3):137-43.
17. Litterio NJ, Calvinho LF, Flores MM, Tarabla HD, Boggio JC. Microbiological screening test validation for detection of tylosin excretion in milk of cows with low and high somatic cell counts. J Vet Med A Physiol Pathol Clin Med. 2007:54(1):30-5.

18. Kim EY, Gebru E, Lee JS, Kim JC, Park SC. Pharmacokinetics of a florfenicoltylosin combination after intravenous and intramuscular administration to beagle dogs. J Vet Med Sci. 2011;73(4):463-6.

19. Levison ME. Pharmacodynamics of antimicrobial drugs. Infect Dis Clin N Am. 2004;18:451-65

20. Sidhu PK, Landoni MF, Aliabadi FS, Lees P. PK-PD integration and modeling of marbofloxacin in sheep. Res Vet Sci. 2010:88(1):134-41.

21. Barger A, Fuhst C, Wiedemann B. Pharmacological indices in antibiotic therapy. J Antimicrob Chemotherapy. 2003:52(6):893-8.

22. Sorensen NS, Tegtmeier C, Andresen LO, Pineiro M, Toussaint MJM, Campbell FM, et al. The porcine acute phase protein response to acute clinical and subclinical experimental infection with Streptococcus suis. Vet Immunol Immunopathol. 2006;113(1-2):157-68.

23. Abu-Basha EA, Al-Shunnaq AF, Gehring R. Comparative pharmacokinetics and bioavailability of two tylosin formulations in chickens after oral administration. J Vet Med Society. 2012;63(2):159-66.

24. Ziv G, Creveld CV, Ben-Zvi Z, Glickman A, Yagil R. Disposition kinetics of tylosin tartrate administered intravenously and intramuscularly to normal and water-deprived camels. J Vet Pharmacol Ther. 1995;18(4):299-305.

25. Taha AA, Elsheikh HA, Khalafalla AE, Osman IA, Abdullah AS. Disposition kinetics of tylosin administered intravenously and intramuscularly in desert sheep and Nubian goats. Vet J. 1999:158(3):210-5.

26. Kim MH, Gebru E, Chang ZQ, Choi JY, Hwang MH, Kang EH, et al. Comparative pharmacokinetics of tylosin or florfenicol after a single intramuscular administration at two different doses of tylosin-florfenicol combination in pigs. J Vet Med Sci. 2008;70(1):99-102.

27. Saurit AR, Rubio M, Baroni E, San AM, Sanchez S, Boggio JC. Some comparative aspects of the pharmacokinetics of tylosin in buffaloes and cattle. Vet Res Commun. 2002:26(1):49-54.

28. Pridmore A, Burch D, Lees P. Determination of minimum inhibitory and minimum bactericidal concentrations of tiamulin against field isolates of Actinobacillus pleuropneumoniae. Vet Microbiol. 2011;151(3-4):409-12.

29. Aliabadi FS, Ali BH, Landoni MF, Lees P. Pharmacokinetics and PK-PD modelling of danofloxacin in camel serum and tissue cage fluids. Vet J. 2003;165(2):104-18.

30. Owens RCJ, Shorr AF. Rational dosing of antimicrobial agents: pharmacokinetic and pharmacodynamic strategies. Am J Health Syst Pharm. 2009;66(Suppl. (12)):S23-30.

31. Clinical and Laboratory Standards Institute (CLSI). Methods for Determining Bactericidal Activity of Antimicrobial Agents; Approved Guideline. CLSI documend M26AE. 1999:29. ISBN Number: 1-56238-384-1

32. Blondeau JM, Shebelski SD, Hesje CK. Killing of Streptococcus pneumoniae by azithromycin, clarithromycin, erythromycin, telithromycin and gemifloxacin using drug minimum inhibitory concentrations and mutant prevention concentrations. Int J Antimicrob Agents. 2015;45(6):594-9.

33. Gingerich DA, Baggot JD, Kowalski JJ. Tylosin antimicrobial activity and pharmacokinetics in cows. Can Vet J. 1977;18(4):96-100.

\section{Ready to submit your research? Choose BMC and benefit from:}

- fast, convenient online submission

- thorough peer review by experienced researchers in your field

- rapid publication on acceptance

- support for research data, including large and complex data types

- gold Open Access which fosters wider collaboration and increased citations

- maximum visibility for your research: over $100 \mathrm{M}$ website views per year

At $\mathrm{BMC}$, research is always in progress.

Learn more biomedcentral.com/submission 